\title{
What Women Want in a Man: The Role of Age, Social Class, Ethnicity, and Height
}

\author{
Adrian Furnham 1,2, Alastair McClelland ${ }^{3}$ \\ ${ }^{1}$ Research Department of Clinical, Educational and Health Psychology, University College London, London, UK \\ ${ }^{2}$ Norwegian Business School (BI), Olso, Norway \\ ${ }^{3}$ Research Department of Experimental Psychology, University College London, London, UK \\ Email: a.furnham@ucl.ac.uk
}

Received 1 February 2015; accepted 22 February 2015; published 26 February 2015

Copyright (C) 2015 by authors and Scientific Research Publishing Inc.

This work is licensed under the Creative Commons Attribution International License (CC BY).

http://creativecommons.org/licenses/by/4.0/

c) (i) Open Access

\begin{abstract}
This study aimed to use a budget allocation model to examine mate preference. 303 female respondents with a mean age of $\mathbf{2 1 . 7 5}$ years were asked about their preferences for someone to take on a blind date. They were presented with descriptions of 16 hypothetical men which they were asked to rate for personal choice and suitability. The hypothetical men differed on age (18 - 20 years vs. 30 - 33 years), social class (I/II vs. III/IV), ethnicity (Caucasian vs. Asian) and height (short/average from 5'6" to 5'8" and tall 6'1" to 6'3"). Overall females preferred younger, taller males from their own racial group and with a higher social class. Women showed a strong preference for men their own age, ethnicity and especially height.
\end{abstract}

\section{Keywords}

Age, Ethnicity, Social Class, Mate Choice

\section{Introduction}

There is now a growing literature on the topic of mate preferences and selection (Candolin, 2003; Kurzban \& Weeden, 2005; Place, Todd, Penke, \& Asendorpf, 2010; Mays \& Hill, 2004; Shackelford, Schmitt, \& Buss, 2005; Schwarz \& Hassebrauck, 2012; Stanik, Kurzban, \& Ellsworth, 2010; Wong \& Candolin, 2005; Wood \& Brumbaugh, 2009). There are some differences with respect to mate choice in long and short term relationships (Li \& Kenrick, 2006); this paper focuses on long term relationships. Two major findings with regards to sex differences in mate selection criteria were noted by Buss (1985) who found women are more concerned with a prospective partner's potential earning ability, while men pay relatively more attention to physical factors, such as attractiveness and health. 
This study focuses on the relative power of social status over three other desirable characteristics among females. Male preferences for female mates have been extensively investigated.

Buss and Angleitner (1989) examined mate preferences in Germany and the United States. Participants were asked to rank 13 characteristics on their desirability of a potential mate. Consistent sex differences were found in participants of both countries, where females ranked good earning potential higher and males ranked physical attractiveness higher. Recent studies have also showed that intelligent men are always appealing to women (Prokosch, Coss, Scheib, \& Blozis, 2009).

Studies in mate selection and preference fall into various further categories: content analysis of "lonely hearts" columns (Harrison \& Saeed, 1977; Greenless \& McGrew, 1994); post "commercial date” speed interactions ratings (Kurzban \& Weeden, 2005); psychometric studies on hypothetical, prototypic people with known specified characteristics; as well as ratings of pictures/photographs of individuals (Wood \& Brumbaugh, 2009). However, more recent studies have looked at specific features of mate preferences (Fletcher, Simpson, Thomas, \& Giles, 1999) as well as trade-offs and compromises in mate choice (Shackleford et al., 2005); and the effect of selfappraisal on mate choice (Kenrick, Groth, Trost, \& Sadalla, 1993). Kurzban and Weeden (2005) found the agreedupon mate values for both sexes were related almost entirely to observable physical attributes like age, attractiveness, Body Mass Index (BMI) and height and not those less observable characteristics like education, religion, socio-sexuality or ideas about children.

More recent research has specified the role of personality factors (Wood \& Brumbaugh, 2009) in mate selection. Klohnen and Luo (2003) used a couple-centred approach and looked at newlyweds' assortative mating issues. Results showed that on 19 of the 21 domains under investigation, real couples were more similar than randomly paired couples, and evidence consistent with spouse similarity but none for complementarity.

Furnham (2009) asked 230 young people to rate 14 desirable characteristics classified under five headings (ability, personality, physical, social and values). Females rated intelligence, stability, conscientiousness, height, education, social skills and political/religious compatibility significantly higher than males, who rated good looks higher than females. Regressions showed sex, personality and ideology were consistently related to partner preference.

Various recent studies have confirmed the importance of a male mates "good financial prospects" as well as cues to fertility (such as youth) (Chang, Wang, Shackelford, \& Buss, 2011). Some studies have looked at the relative importance of mate characteristics on preferences (Li \& Kenrick, 2006; Fletcher, Tither, O’Loughlin Friesen, \& Overall, 2004). They directly compared the relative effect sizes of different traits. Recently Li, Valentine and Patel (2011) used a preference priority model to show that both in American and Singapore men prioritise physical attractiveness and women social status.

The study follows the method used in studies on the allocation of scarce medical (and other resources) (Furnham, Ariffin, \& McClelland, 2007). These studies describe people vignettes which are systematically varied and which are then rated. Previous studies seem to suggest that people have strong preferences for individuals like themselves in terms of age, social class and ethnicity. That is-there is evidence of assortative mating.

This paper also investigated height which has attracted a good deal of recent research (Mueller \& Mazur, 2001; Nettle, 2002; Pawlowski, 2003; Pawlowski, Dunbar, \& Lipowicz, 2000; Sear, 2006; Stulp, Pollet, Verhulst, \& Buunk, 2012; Stulp, Buunk, Pollet, Nettle, \& Verhulst, 2013).

In this study participants were given short vignettes describing a male on four dimensions in a $2 \times 2 \times 2 \times 2$ experimental design. The four dimensions were age (18 - 21 vs. 30 - 33), profession (occupations in social class I/II vs. III/IV), ethnicity (Caucasian vs. Asian) and height (average vs. tall). The following predictions were made. H1: "Younger" people would be chosen over "older" because of their fitness, H2: Social class I (A or Professional) over III (C or trades person) because it is a marker of intelligence and the ability to acquire resources through well paid work; H3: Caucasian over Asian to match race of rater with hypothetical recipient (and themselves); and H4: Tall over average height. There were also a number of between participant factors of interest namely age, height and race. It was anticipated that there would be a similarity effect for each of these factors such that older participants would prefer older males (H5); taller participants would choose taller males (H6) and that people would prefer a partner from their own racial group (H7).

\section{Method}

\subsection{Participants}

The participants of this study were 303 females ranging in age from 17 to 36 years $(M=21.75, S D=6.65)$. In 
all 73\% had a school leaving certificate as their highest qualification while the remainder were graduates. The sample, tested in London, was mainly British consisted primarily of Caucasian participants (66.7\% Caucasian) but also 25.9\% Asian; 2\% African as well a 5.4\% unspecified “other”. Most were single (54.7\%), 20\% with a long term partner, $17.3 \%$ with a short term partner, $6 \%$ married; $2 \%$ “other”. In all 92.6\% said there were heterosexual, $1.7 \%$ homosexual and 5.7\% “other". They also reported their weight in kilograms $(M=57.15)$ and their height in centimetres $(M=165.25)$.

\subsection{Materials}

All participants completed a two-part questionnaire comprising the Great Date questionnaire and a section of demographic questions. The construction of the questionnaire was based on techniques used in previous studies to assess patient prioritisation for the allocation of scarce medical resources (e.g., Furnham, Ariffin, \& McClelland, 2007; Furnham, Hassomal, \& McClelland, 2002; Furnham, Thomas, \& Petrides, 2002; Furnham, Thomson, \& McClelland, 2002). This resource allocation method has been used successfully in a number of papers in this area.

All participants were first asked to imagine the following:

A great date: We want you to imagine the following. A local dating service has provided a short list of men looking for "a serious relationship”. You are in the same position. They are trying to "pair-up” people who will "get on" and indeed have a happy long-term relationship, they have developed a short list of 16 people. Your task is to rate whether you are interested in meeting them for an initial date.

There are 16 choices. Please rate each on an 8-point scale, where

\section{0 = Definitely No and 8 = Definitely Yes}

Participants were then presented with a short description of 16 hypothetical dates who they rated for suitability using a 9-point scale ( 0 = Definitely No and 8 = Definitely Yes). Each male varied on the following four characteristics: age (young/old), occupation (non-professional/professional), ethnicity (European Caucasian/Asian), and height (from 5'6” to 5'8” and from 6'1" to 6'3”). Class was indicated by profession.

Each male was one particular example of the 16 possible combinations of the four characteristics. For example:

Male A, aged 30, is a lawyer. He is 6’2” (188 cm) and of European (Caucasian) descent.

Male B, is an Asian, 19 years old, 5’8” $(173 \mathrm{~cm})$ and an apprentice electrician.

Male C, 5'6” (168 cm), is a 20-year-old European (Caucasian) male. He has just started a degree in Medicine.

All participants were required to make their decisions based solely on this information.

In the second part of the questionnaire, participants reported their demographic information, which included age, ethnicity, marital status, number of children, current occupation, and religious affiliation.

\subsection{Procedure}

Ethical permission was first sought and obtained. Participants were recruited opportunistically from their place of work or study by a dozen research assistants given clear instructions for sampling. They were told it was a study on dating preferences. Responses to the questionnaire were not time constrained and participants were permitted to return them at a later date. All participants were instructed to complete the questionnaire individually and anonymously. Following completion of the study, where possible, participants were fully debriefed. The response rate was over $90 \%$.

\section{Results}

Complete data was available for 263 participants on the three judge characteristics (between-subjects variables) and the four date variables (within-subjects variables). Median-spits were conducted on the ages and heights of the judges to create two binary variables (age: younger, older and height: shorter, taller, respectively). A 2 (age of judge) $\times 2$ (ethnicity of judge) $\times 2$ (height of judge) $\times 2$ (age of date) $\times 2$ (social class of date) $\times 2$ (ethnicity of date) $\times 2$ (height of date) mixed ANOVA was conducted and the following results were obtained. 


\subsection{Judge Characteristics}

None of the main effects were significant; age and height, $F \mathrm{~s}<1$, and ethnicity, $F(1,255)=1.13, p>0.05\left(\eta_{p}^{2}\right.$ $=0.4 \%$ ). There were no significant two-way interactions between the judge characteristics, all $F \mathrm{~s}<1$. The threeway interaction was not significant, $F(1,255)=1.69, p>0.05\left(\eta_{p}^{2}=0.7 \%\right)$.

\subsection{Date Characteristics}

The mean ratings given to the 16 descriptions of the potential dates are presented in Table 1 .

There was a significant main effect of age, $F(1,255)=24.25, p<0.001\left(\eta_{p}^{2}=8.7 \%\right)$ with younger men $(M=$ $3.55)$ being preferred to older men $(M=2.85)$. There was a very strong effect of social class, $F(1,255)=205.60$, $p<0.001\left(\eta_{p}^{2}=44.6 \%\right)$ with men from a higher social class $(M=3.66)$ preferred over men from a lower social class $(M=2.73)$. There was also a main effect of ethnicity, $F(1,255)=44.17, p<0.001\left(\eta_{p}^{2}=14.8 \%\right)$ with Caucasian men $(M=3.47)$ being preferred to Asian men $(M=2.93)$. Finally there was a main effect of height, $F$ $(1,255)=12.04, p<0.001\left(\eta_{p}^{2}=4.5 \%\right)$ with taller men $(M=3.32)$ preferred to shorter men $(M=3.08)$.

\subsection{Two-Way Interactions between a Judge Characteristic and a Date Characteristic}

There were a number of two-way interactions between the characteristics of the judges and the potential dates. As predicted, there was a highly significant cross-over interaction between the age of the judge and the age of the date (see Figure 1), $F(1,255)=111.19, p<0.001\left(\eta_{p}^{2}=30.4 \%\right)$.

Simple effects analysis revealed that amongst younger judges, younger men $(M=4.33)$ were much preferred over older men $(M=2.15), F(1,117)=133.56, p<0.001\left(\eta_{p}^{2}=53.3 \%\right)$, whereas the reverse was true for older judges who preferred older men $(M=3.55)$ over younger men $(M=2.76), F(1,138)=14.40, p<0.001\left(\eta_{p}^{2}=\right.$ 9.4\%). There was also a cross-over interaction between the ethnic background of the judge and the date (see Figure 2), $F(1,255)=60.61, p<0.001\left(\eta_{p}^{2}=19.2 \%\right)$.

Simple effects analysis revealed that Asian judges were indifferent to the ethnicity of their potential date (Asian: $M=3.34$, Caucasian: $M=3.25$ ), $F<1$, but among the Caucasian judges there was a strong preference for Caucasian males (Asian: $M=2.51$, Caucasian: $M=3.69), F(1,183)=196.57, p<0.001\left(\eta_{p}^{2}=51.8 \%\right)$. There was also an interaction between the height of the judge and the height of the date (see Figure 3$), F(1,255)$ $=11.16, p<0.001\left(\eta_{p}^{2}=4.2 \%\right)$.

Table 1. Mean ratings as a function of age, social class, ethnicity and height.

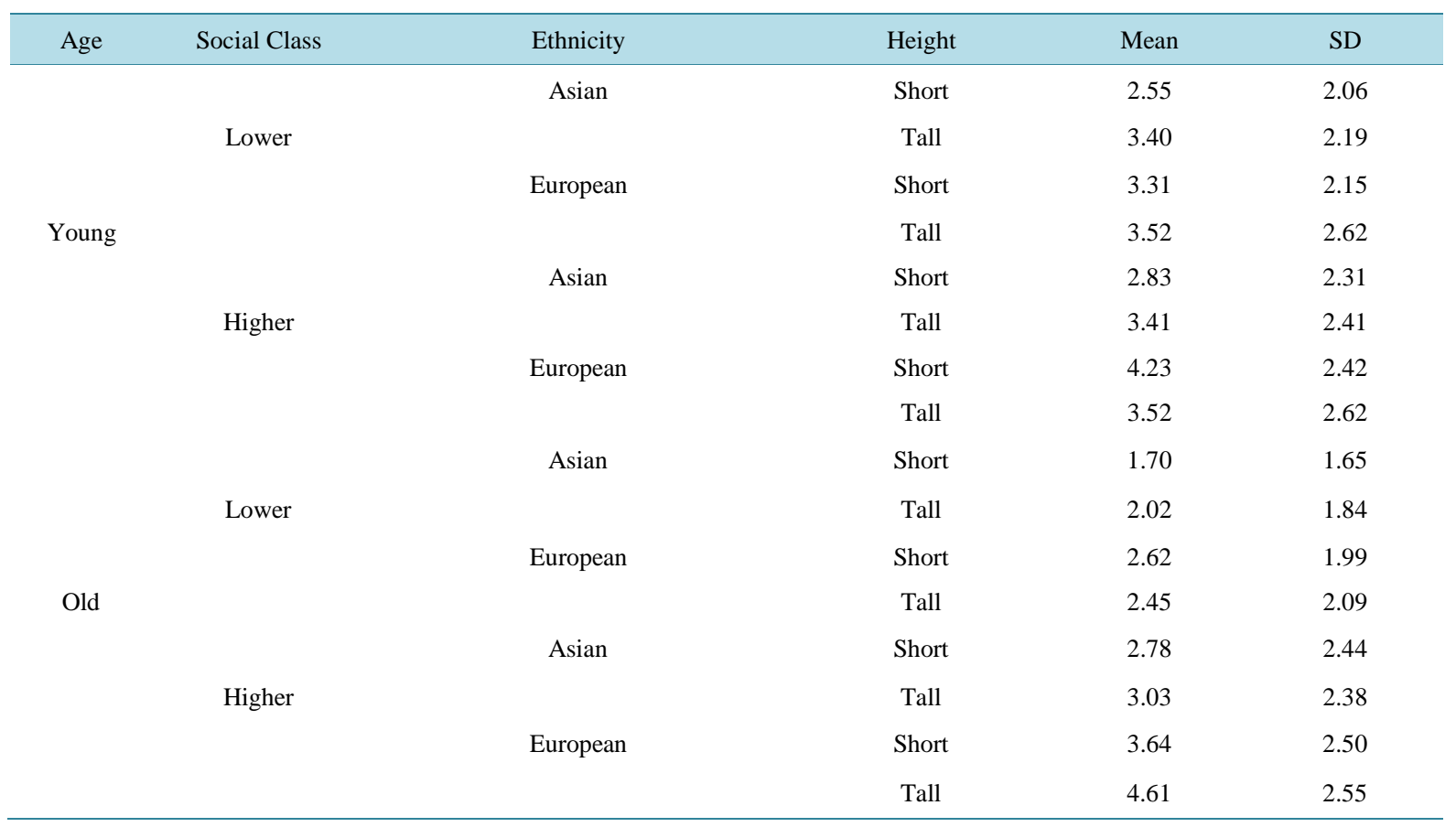




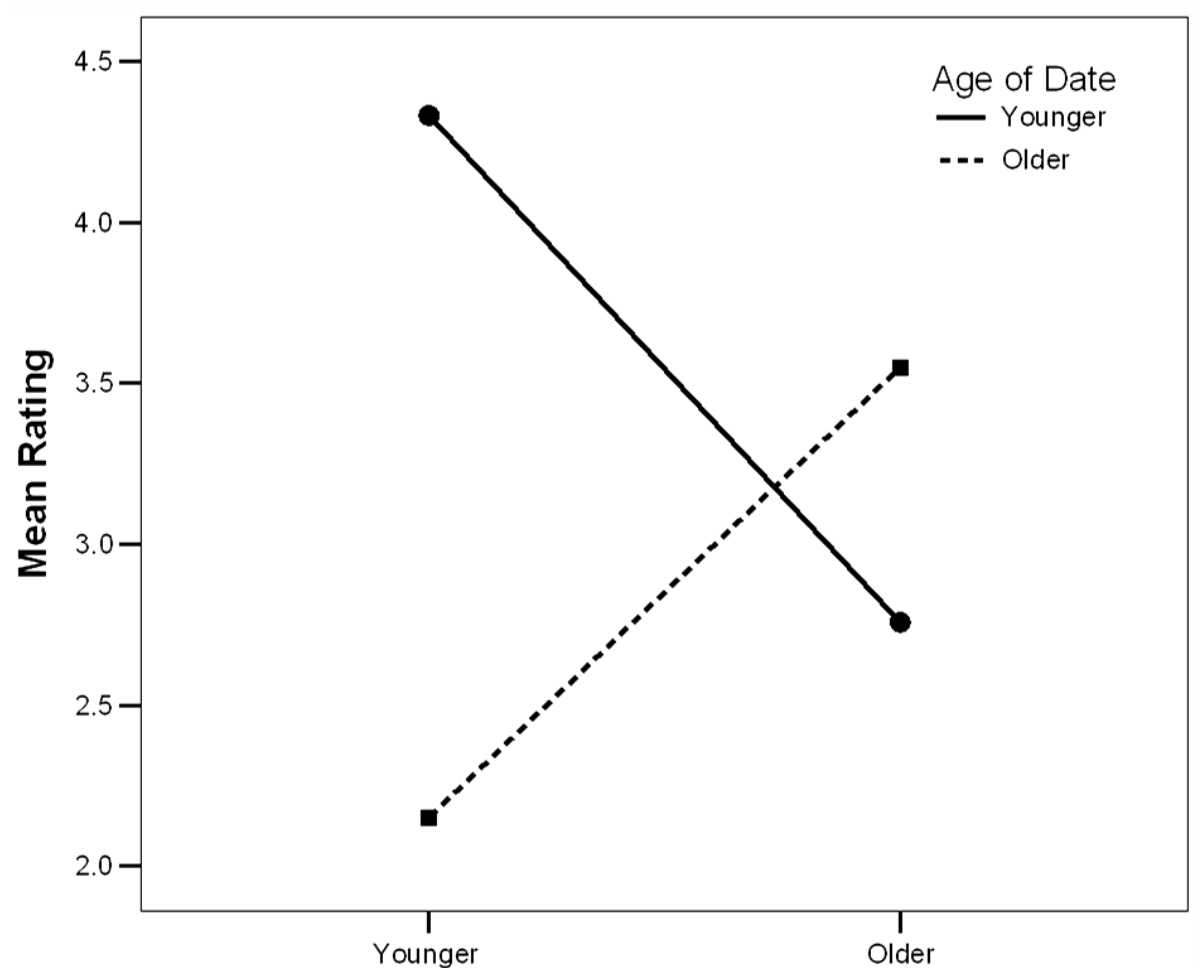

Figure 1. Showing main effects and interaction of age of date and age of judge for mean ratings.

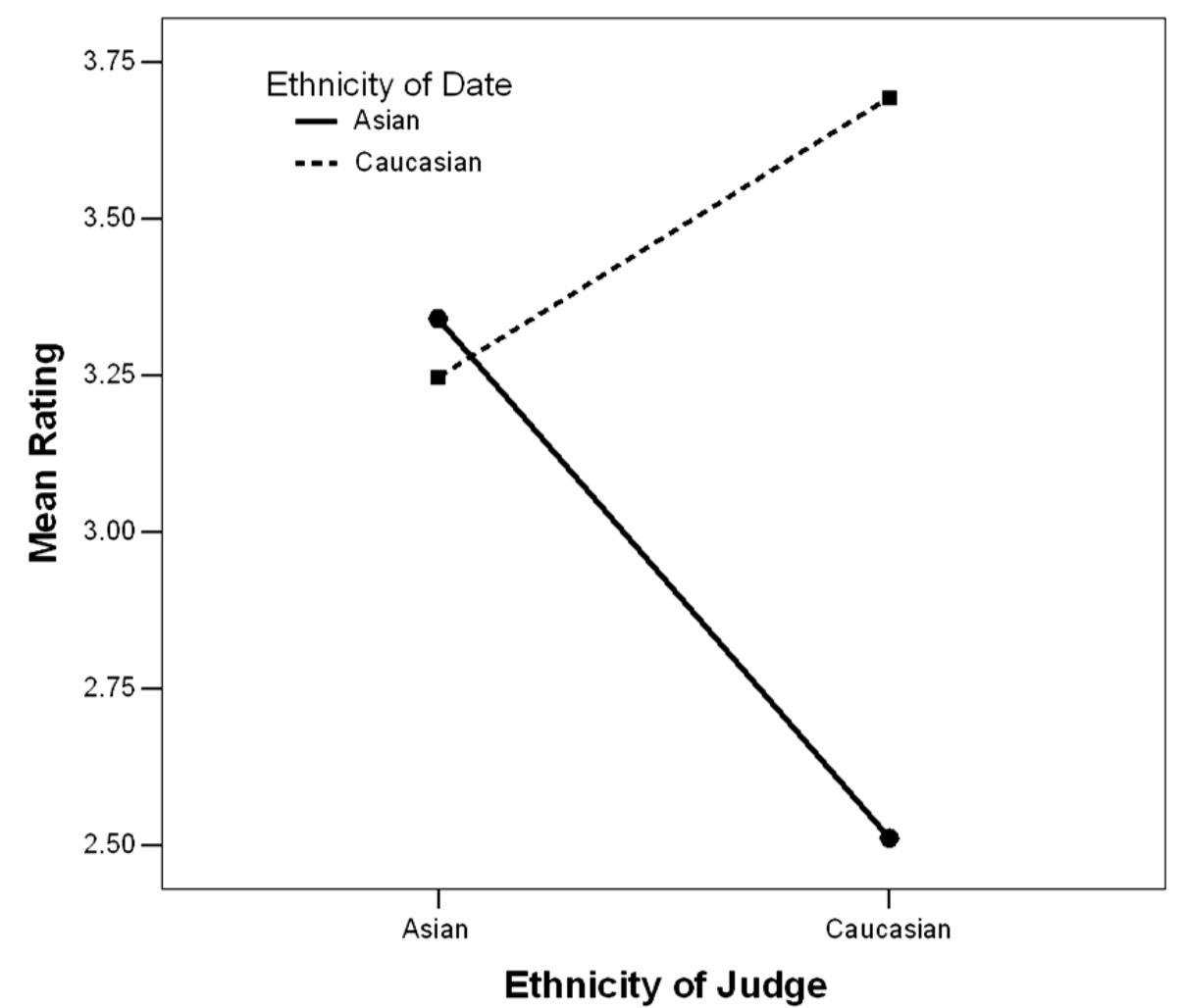

Figure 2. Showing main effects and interaction of ethnicity of date and ethnicity of judge for mean ratings. 


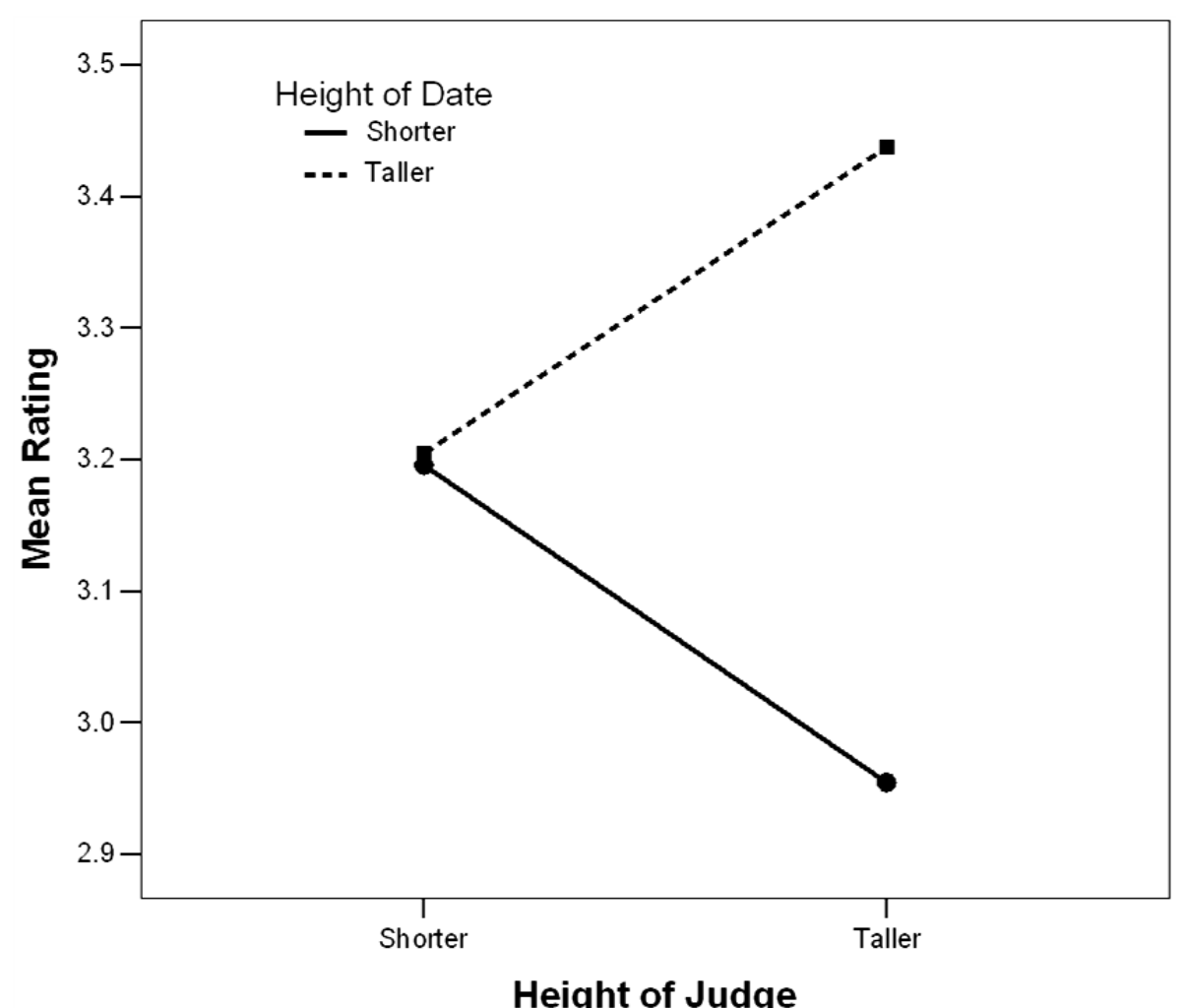

Figure 3. Showing main effects and interaction of height of date and height of judge for mean ratings.

Short judges were indifferent to the height of the potential date (Shorter: $M=3.20$, Taller: $M=3.21$ ), $F<1$, but taller judges preferred taller males $(M=3.44)$ to shorter males $(M=2.95), F(1,135)=13.89, p<0.001\left(\eta_{p}^{2}\right.$ $=9.3 \%)$. The height of the date also interacted with the ethnicity of the judge (see Figure 4 ), $F(1,255)=7.39$, $p<0.01\left(\eta_{p}^{2}=2.8 \%\right)$.

Asian judges were indifferent to the height of the date (Shorter: $M=3.27$, Taller: $M=3.32$ ), $F<1$, but Caucasian judges preferred taller men $(M=3.32)$ over shorter men $(M=2.88), F(1,183)=30.31, p<0.001\left(\eta_{p}^{2}=\right.$ $14.2 \%)$. There was also a significant interaction between the age of the judge and the social status of the date (see Figure 5), $F(1,255)=8.64, p<0.01\left(\eta_{p}^{2}=3.3 \%\right)$.

Younger judges preferred men from a higher social class $(M=3.61)$ to those from a lower social class $(M=$ 2.67), $F(1,117)=63.94, p<0.001\left(\eta_{p}^{2}=35.5 \%\right)$, and the same pattern was observed in older judges-but the effect was stronger (Upper Social Class: $M=3.72$, Lower Social Class: 2.59$), F(1,138)=151.01, p<0.001$ $\left(\eta_{p}^{2}=52.3 \%\right)$. There was also a significant interaction between the ethnicity of the judge and the social status of the date (see Figure 6), $F(1,255)=13.37, p<0.001\left(\eta_{p}^{2}=5.0 \%\right)$.

Males from a lower social class received similar ratings from both Asian $(M=2.71)$ and Caucasian $(M=2.75)$ judges, $F<1$, but Asian judges gave higher ratings to higher social class males $(M=3.88)$ than did Caucasian judges $(M=3.45), F(1,255)=4.55, p<0.05\left(\eta_{p}^{2}=1.8 \%\right)$.

\subsection{Two-Way Interactions between Date Characteristics}

Age interacted with ethnicity (see Figure 7), $F(1,255)=8.43, p<0.01\left(\eta_{p}^{2}=3.2 \%\right)$.

Simple effects analysis revealed that within Asian males, younger men $(M=3.36)$ were greatly preferred over older men $(M=2.49), F(1,255)=41.03, p<0.001\left(\eta_{p}^{2}=13.9 \%\right)$. A similar pattern was evident within Caucasians males but the effect was attenuated; (Younger Men: $M=3.73$, Older Men: $M=3.21), F(1,255)=9.37, p$ $<0.01\left(\eta_{p}^{2}=3.5 \%\right)$. There was a strong interaction between age and social class (see Figure 8), $F(1,255)=$ 138.97, $p<0.001\left(\eta_{p}^{2}=35.3 \%\right)$.

Simple effects analysis showed that for males from a lower social class, younger men $(M=3.38)$ were greatly 


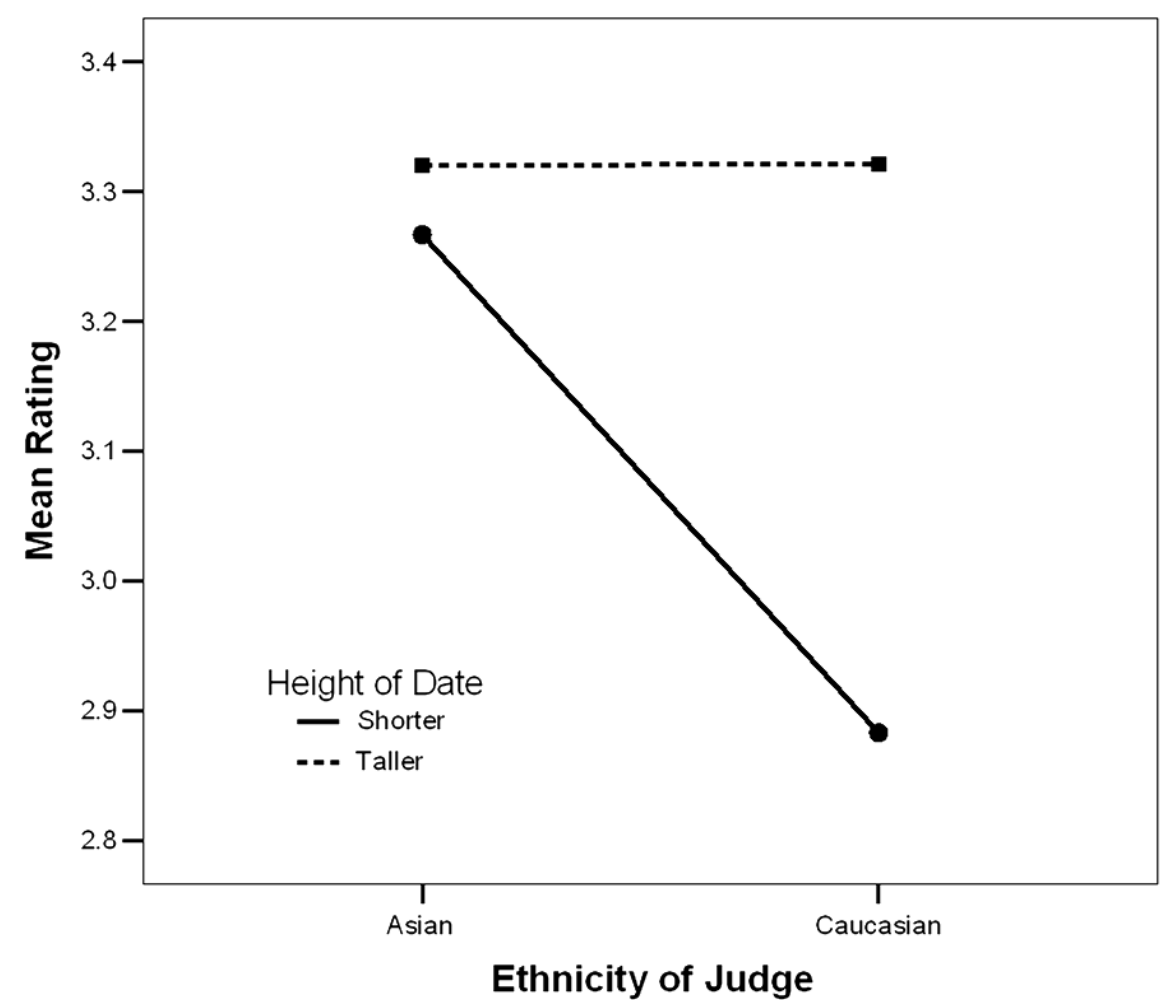

Figure 4. Showing main effects and interaction of height of date and ethnicity of judge for mean ratings.

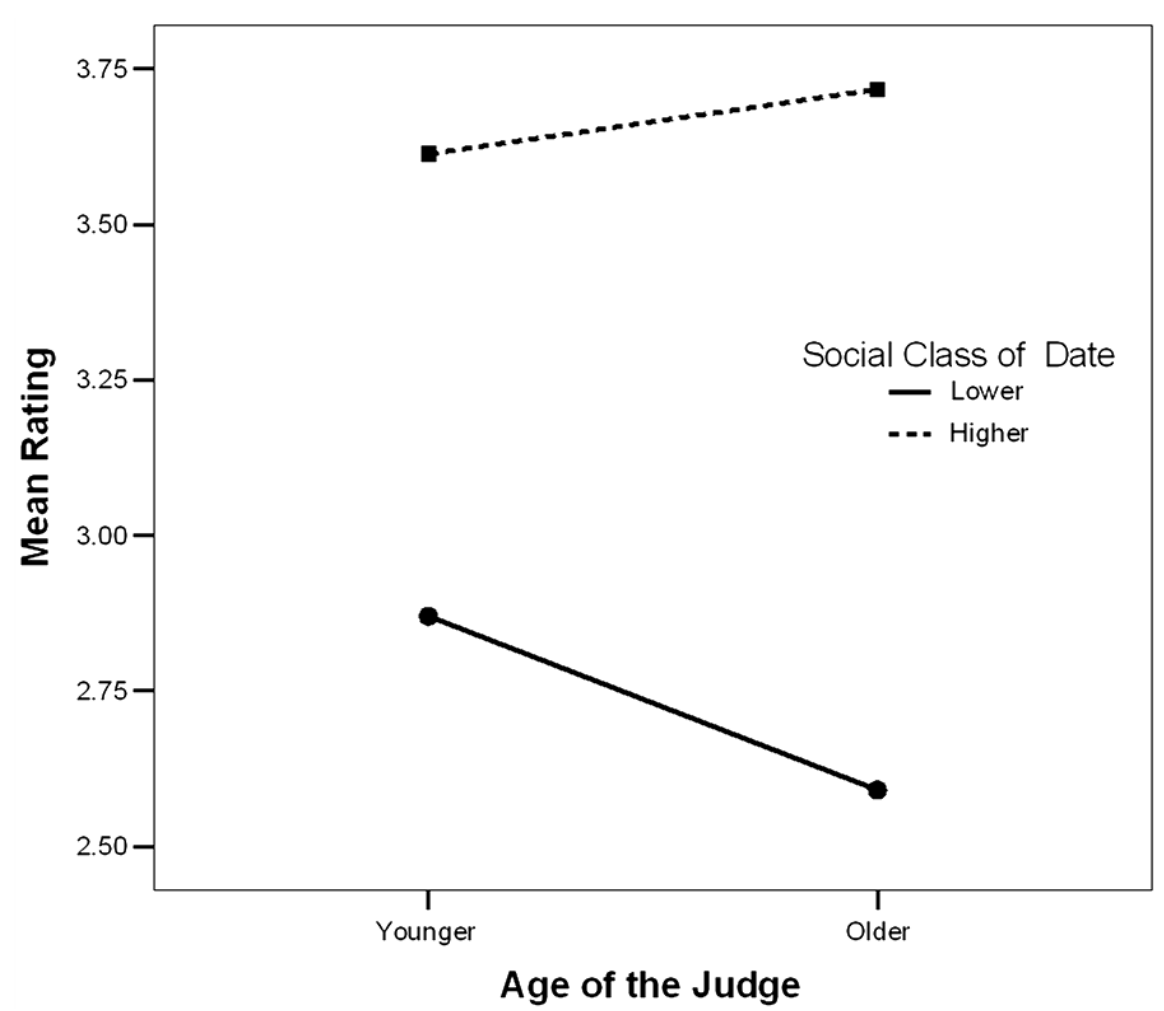

Figure 5. Showing main effects and interaction of social class of date and age of judge for mean ratings. 


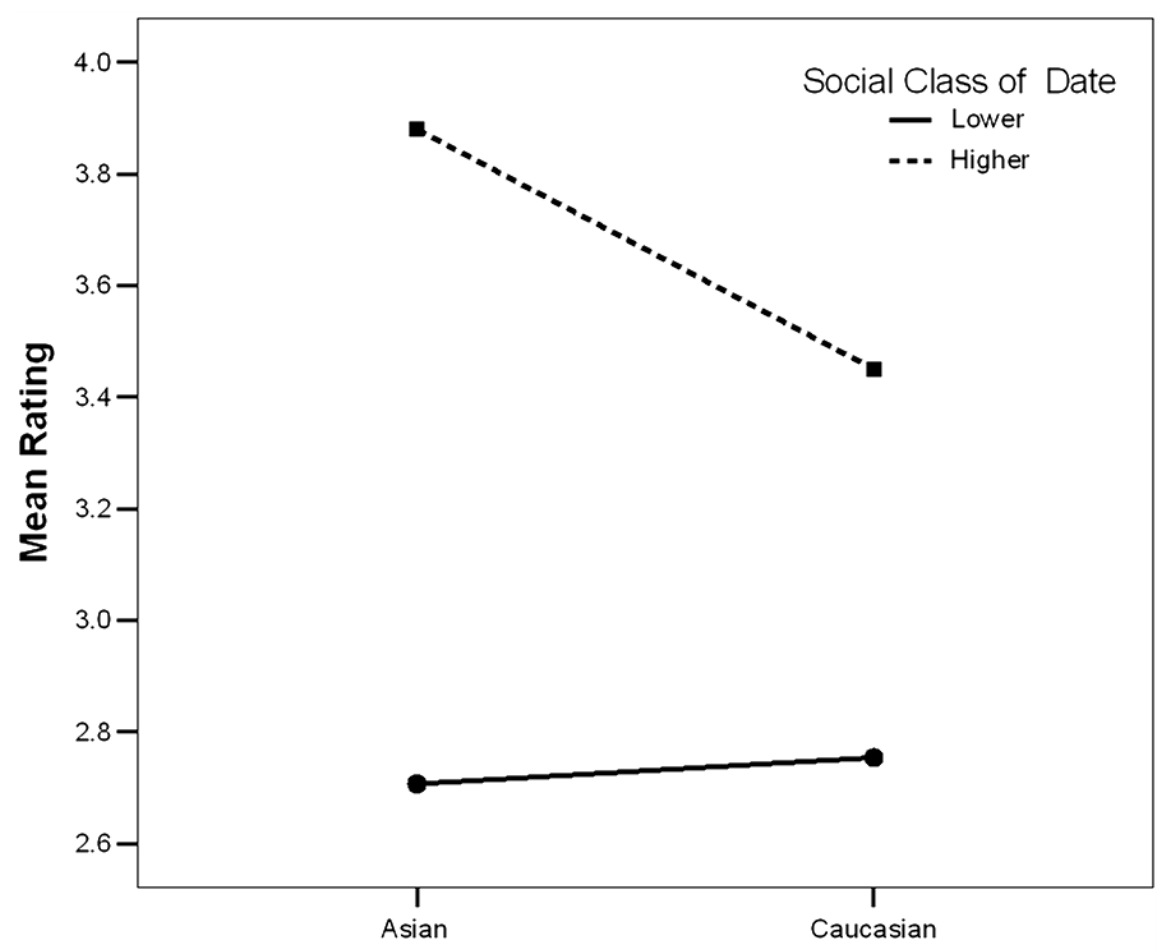

Ethnicity of the Judge

Figure 6. Showing main effects and interaction of social class of date and ethnicity of the Judge for mean ratings.

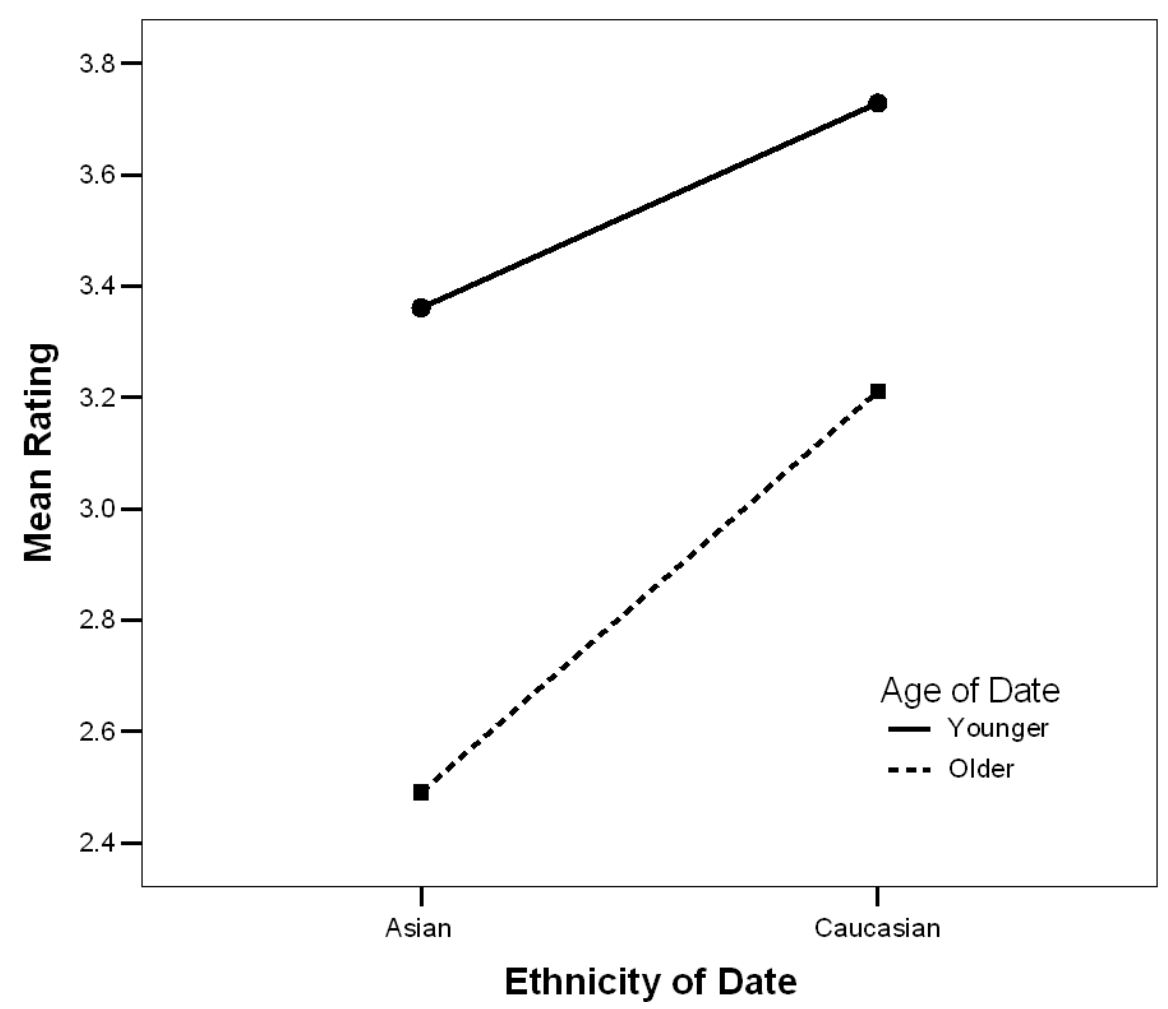

Figure 7. Showing main effects and interaction of age of date and ethnicity of date for mean ratings. 


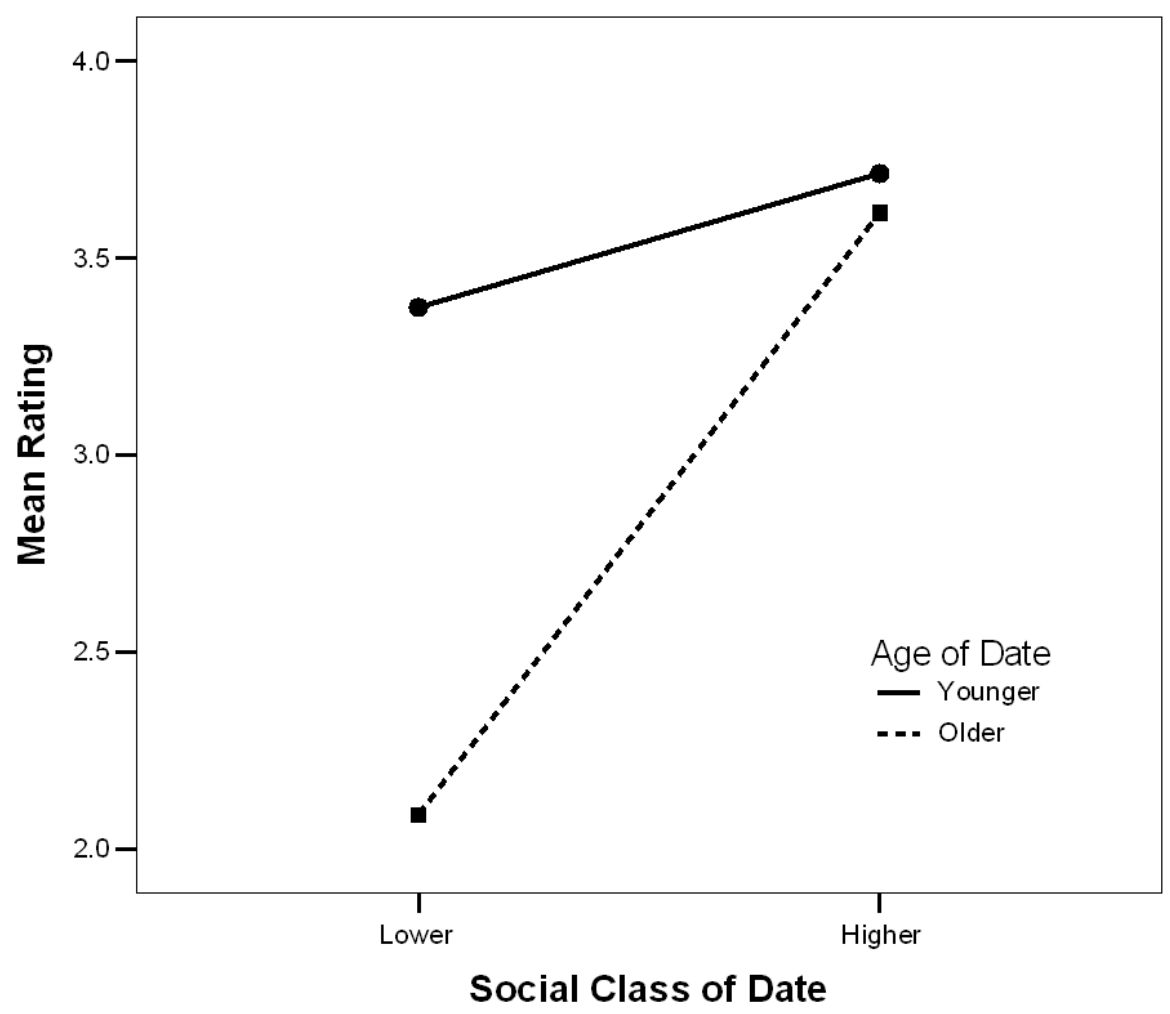

Figure 8. Showing main effects and interaction of age of date and social class of date for mean ratings.

preferred over older men $(M=2.09), F(1,255)=90.83, p<0.001\left(\eta_{p}^{2}=26.3 \%\right)$, but for males from a higher social class there was no age effect (Lower Class: $M=3.72$, Higher Class: $M=3.62) F<1$. Height interacted significantly with ethnicity (see Figure 9), $F(1,255)=31.47, p<0.001\left(\eta_{p}^{2}=11.0 \%\right)$.

Within Asian males, taller men $(M=3.21)$ were preferred to shorter men $(M=2.65), F(1,255)=65.35, p<$ $0.001\left(\eta_{p}^{2}=20.4 \%\right)$, whereas amongst Caucasian males, there was no effect of height (Shorter: $M=3.5$, Taller: $M=3.44$ ), $F<1$. The final two-way interaction was between ethnicity and social class (see Figure 10), $F(1$, 255) $=13.19, p<0.001\left(\eta_{p}^{2}=4.9 \%\right)$.

In this case simple effects analysis revealed that in both ethnic groups men from a higher social class were preferred over those from a lower social, but this effect was stronger amongst Caucasian men (Higher Social Class: $M=4.02$, Lower Social Class: $M=2.92), F(1,255)=206.52, p<0.001\left(\eta_{p}^{2}=44.7 \%\right)$ than amongst Asian men (Higher Social Class: $M=3.31$, Lower Social Class: $M=2.54), F(1,255)=90.95, p<0.001\left(\eta_{p}^{2}=\right.$ 26.3\%).

\subsection{Higher Order Interactions}

Of the remaining significant interactions, seven were three-way, five four-way, one five-way and one six-way. Interested readers can contact the second author for full details of these results.

\section{Discussion}

The present study results indicated that overall females preferred younger (H1), taller (H4) males from their own racial group (H3) and with a higher social class (H2) as opposed to shorter, older, Asian men from a lower social class. Further there were significant two-way interactions between the judge and the date characteristic for age (H5), ethnicity (H7) and height (H6). Two-way interactions between date characteristics were also found showing younger Asian males were preferred over older Asian males; younger males from a lower social class were preferred over older males from a lower social class and taller Asian males were preferred to shorter Asian males; whereas amongst Caucasian males there was no effect of height. 


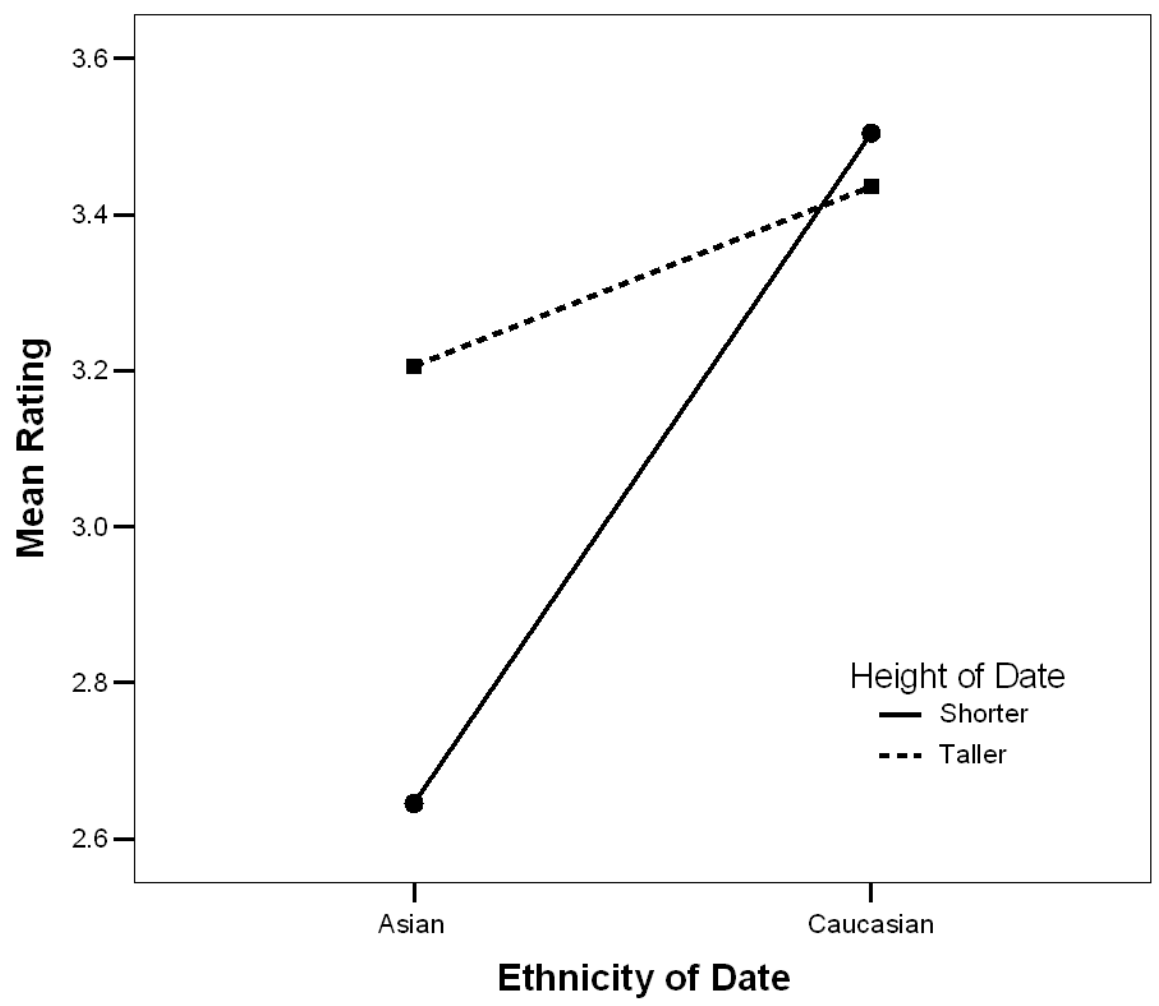

Figure 9. Showing main effects and interaction of height of date and ethnicity of date for mean ratings.

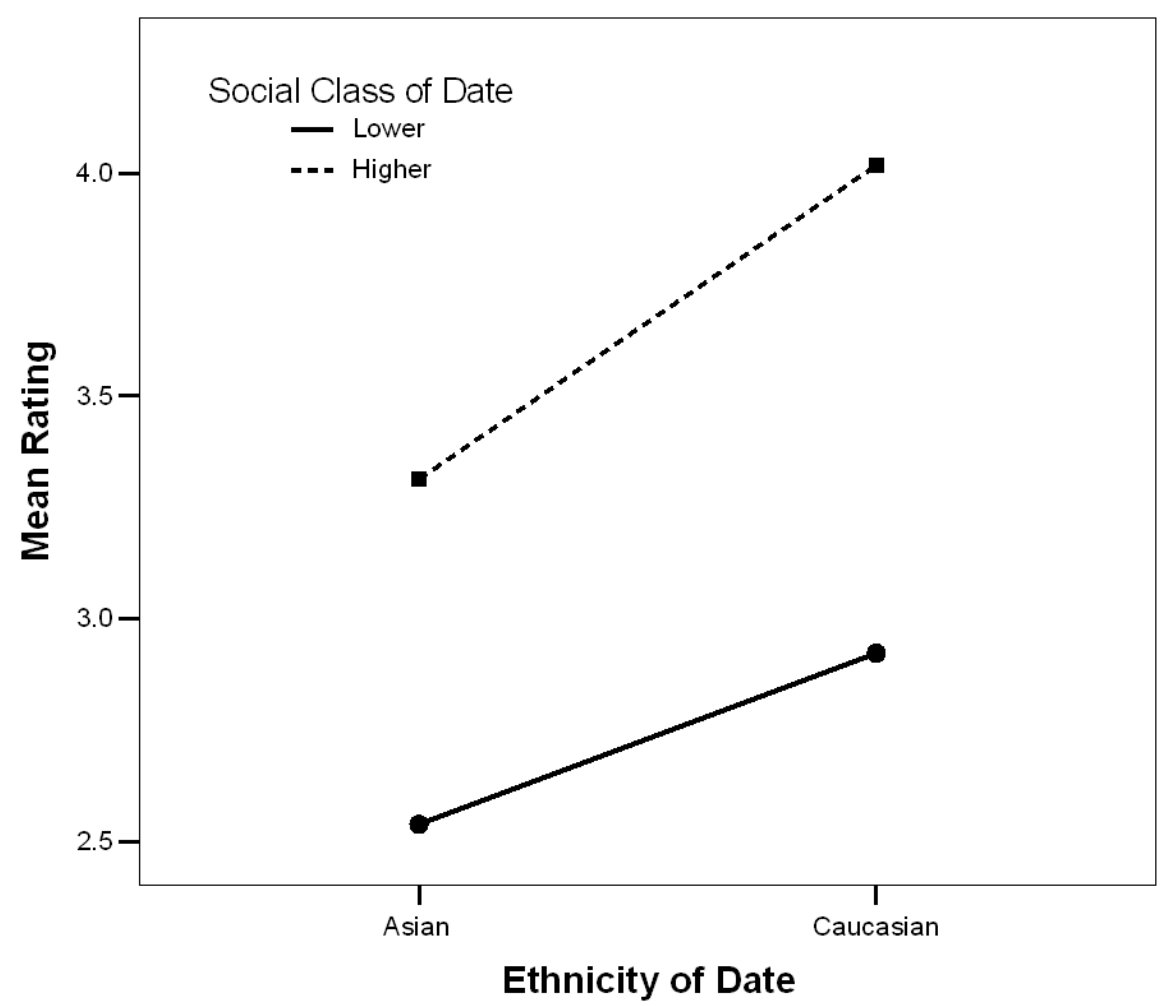

Figure 10. Showing main effects and interaction of social class of date and ethnicity of date for mean ratings. 
These results confirmed previous research on mate selection criteria (Buss, 1985; Buss \& Angleitner, 1989) suggesting several factors are important when selecting a date. The effect of social class or profession was very strong in this study with men from a higher social class (e.g., lawyer) being preferred over men from a lower social class (e.g., electrician). The effect size for class was much higher than the other three factors. Social class is an index of education and wealth and is a signal to a female of the male's potential command over resources.

We used profession as a well know indicator of social class and financial remuneration. It has been established that people are accurate in knowing the salaries of people in different professions (Furnham \& Wilson, 2011). Profession could also be seen as a proxy for intelligence, which lay people see both as heritable and a marker of economic success and therefore a resource acquisition (Furnham, 1988). Previous studies have shown that women favour intelligent men because it is seen as a cue for provisioning abilities (Prokosch, Coss, Scheib, \& Bozis, 2009). Profession might also be an indicator of other characteristics to observers like education, educability and conscientiousness as well as specific abilities. Certainly it is used widely in situations where people describe themselves and "advertise" for a mate (Furnham, 2009). Thus even for a "blind date" social status is seen as more important than other potentially influential factors like ethnicity.

Further, two-way interactions were found, indicating that judges preferred men from a higher social class ( $M$ $=3.61)$ to those from a lower social class $(M=2.67)$. Interestingly males from a lower social class received similar ratings from both Asian and Caucasian judges but Asian judges gave higher ratings to higher social class ( $M$ = 3.88) than did Caucasian $(M=3.45)$. Furthermore, there was a strong interaction showing that among males from a lower social class younger men were greatly preferred over older men, possibly because they had greater opportunity to climb the social class ladder.

Studies have shown that women favour intelligent men because intelligence is seen as a cue for provisioning abilities (Prokosch, Coss, Scheib, \& Bozis, 2009). This study provided additional evidence for this hypothesis suggesting age, height, ethnicity and social class play a significant but less important role in dating decisions. Profession might also be an indicator of other characteristics to observers like education, educability and conscientiousness as well as specific abilities. Certainly it is used widely in situations where people describe themselves and "advertise" for a mate (Furnham, 2009). Thus it seems people believe that those which high socio-economic status pass on some genetic propensity (particularly intelligence) that leads to occupational success.

Interestingly the main effect of height was least important in this study, though much more important to taller women. Participants preferred a taller potential date over an older date but this was also affected by the height of the judge; where short judges were indifferent to the height of the potential date, but taller judges preferred taller males $(M=3.44)$ to shorter males $(M=2.95)$. Further there was a significant two-way interaction between height and ethnicity within Asian males, where taller men $(M=3.21)$ were preferred to shorter men $(M=2.65)$; however amongst Caucasian there was no effect of height. This confirms the findings of a study similar to this, by Birenbaum-Carmeli and Carmeli (2002).

There is evidence in the evolutionary psychology literature which shows the particular benefits of height in men (Swami \& Furnham, 2008). What seems most important is the relative height in couples when it is preferable that the male is taller than the female. This gives taller men an advantage because they presumably have a greater choice of females. It is possible this slightly smaller than anticipated effect was due to the height ranges in the study not being enough to show a large effect. Thus if the heights had been more extreme including severely below average height for a man (5'3') and above average (6'6') the results may have been stronger (although averages differ for Caucasian and Asian males so the extremes would need to be ethnically appropriate).

The study also indicated a preference for "younger" men over "older" men, as predicted, with a further cross over effect between younger judges choosing younger men and older judges choosing older men. Unsurprisingly research has consistently shown age to be important in physical attractiveness, especially for males choosing females (Jones \& Hill, 1993), though much less for females choosing males. This effect may have been found due to the participants' age moderating the effect of dating age; over $61 \%$ were either 20 years of age or less. This may have led participants to be more biased towards potential dates of their own age, although the sample was aimed primarily at 18 - 35 year olds to make it relative to the potential daters.

The study showed a main effect of ethnicity with a preference for Caucasian dates over Asian dates across judges. This is particularly interesting as a two-way interaction found Asian judges were indifferent to the ethnicity of their potential date; however, Caucasian judges showed a strong preference for Caucasian males. There are many possible explanations for this finding though it is likely to be moderated by factors such as the rater's 
religion and experience of racial groups other than their own. Furthermore when considering Asian males, taller men were preferred to shorter men.

The study also provided evidence for the use of scarce allocation or preference priority approaches to mate selection (Li et al., 2011). The study also has implications for the application of dating websites where limited information is provided in order to attract potential daters. It is possible due to this importance of these characteristics it indicates certain information should be emphasized in order to attract potential dates. In some countries newspapers and magazines prescribe that personal information is disclosed, even in a particular order such as caste, education, age, skin colour etc.

Studies based on this methodology have obvious limitations. Participants are not making real but hypothetical decisions. Further there is a great difference between going on a date and mating with somebody (Li \& Kenrick, 2006). Whilst these factors may be of great importance for people to agree to a date/meeting with a person they do not guarantee attraction which may be the result of other subtle, biological, even unconsciously perceived factors like posture, smell or voice. Next, the information presented to each participant is minimal and confined to just four variables. It is quite possible that there is other information they might have preferentially sought. Further, the effect size could easily be affected by changing the extremes: thus had the men been very short or tall (two standard deviations above or below the norm) it may be expected that the height factor would have shown stronger effects.

Indeed, the reason why social class may have appeared had such strong effects was because the males were described from primarily social class I and IV as opposed to II and III. Finally, most of the participants were young, well educated people and not sufficiently representative of the population. Indeed this may in part explain the preference for the higher social class "candidates". Nevertheless the technology allows for the testing of specific hypotheses derived from the evolutionary psychology literature.

\section{References}

Birenbaum-Carmeli, D., \& Carmeli, Y. (2002). Psysiognomy, Familism and Consumerism: Preferences among Jewish-Israeli Recipients of Donor Insemination. Social Science and Medicine, 54, 363-376.

http://dx.doi.org/10.1016/S0277-9536(01)00035-1

Buss, D. M. (1985). Human Mate Selection. American Scientist, 73, 47-51.

Buss, D. M., \& Angleitner, A. (1989). Mate Selection Preferences in Germany and the United States. Personality and Individual Differences, 10, 1269-1280. http://dx.doi.org/10.1016/0191-8869(89)90239-0

Candolin, U. (2003). The Use of Multiple Cues in Mate Choice. Biological Reviews, 78, 575-595. http://dx.doi.org/10.1017/S1464793103006158

Chang, L., Wang, Y., Shackelford, T., \& Buss, D. (2011) Chinese Mate Preferences. Personality and Individual Differences, 50, 678-683. http://dx.doi.org/10.1016/j.paid.2010.12.016

Fletcher, G., Simpson, J., Thomas, G., \& Giles, L. (1999). Ideals in Intimate Relationships. Journal of Personality and Social Psychology, 76, 72-89. http://dx.doi.org/10.1037/0022-3514.76.1.72

Fletcher, G., Tither, J., O’Loughin, C., Froesen, M., \& Overall, N. (2004) Warm and Homely or Cold and Beautiful: Sex Differences in Trading off Traits in Mate Selection. Personality and Social Psychology Bulletin, 30, 659-672. http://dx.doi.org/10.1177/0146167203262847

Furnham, A. (1988). Lay Theories. Oxford: Pergamon.

Furnham, A. (2009). Sex Differences in Mate Selection Preferences. Personality and Individual Differences, 47, $622-627$. http://dx.doi.org/10.1016/j.paid.2009.03.013

Furnham, A. F., Hassomal, A., \& McClelland, A. (2002). A Cross-Cultural Investigation of the Factors and Biases Involved in the Allocation of Scarce Medical Resources. Journal of Health Psychology, 7, 381-391. http://dx.doi.org/10.1177/1359105302007004327

Furnham, A., \& Wilson, E. (2011). Gender Differences in Estimated Salaries: A UK Study. Journal of Socio-Economics, 40, 623-630. http://dx.doi.org/10.1016/j.socec.2011.04.019

Furnham, A., Ariffin, A., \& McClelland, A. (2007). Factors Affecting Allocation of Scarce Medical Resources across LifeThreatening Medical Conditions. Journal of Applied Social Psychology, 37, 2903-2921. http://dx.doi.org/10.1111/j.1559-1816.2007.00287.x

Furnham, A., Thomas, C., \& Petrides, K. V. (2002). Patient Characteristics and the Allocation of Scarce Medical Resources. Psychology, Health, and Medicine, 7, 99-106. http://dx.doi.org/10.1080/13548500120101595 
Furnham, A., Thomson, K., \& McClelland, A. (2002). The Allocation of Scarce Medical Resources across Medical Conditions. Psychology and Psychotherapy: Theory, Research and Practice, 75, 189-203. http://dx.doi.org/10.1348/147608302169643

Greenless, I. A., \& McGrew, W. C. (1994). Sex and Age Differences in Preferences and Tactics of Mate Attraction: Analysis of Published Advertisements. Ethology and Sociobiology, 15, 59-72. http://dx.doi.org/10.1016/0162-3095(94)90017-5

Harrison, A. A., \& Saeed, L. (1977). Let’s Make a Deal: An Analysis of Revelations and Stipulations in Lonely Hearts Advertisements. Journal of Personality and Social Psychology, 35, 257-264. http://dx.doi.org/10.1037/0022-3514.35.4.257

Jones, D., \& Hill, K. (1993). Criteria of Facial Attractiveness in Five Populations. Human Nature, 4, 271-296. http://dx.doi.org/10.1007/BF02692202

Kenrick, D., Groth, G., Trost, M., \& Sadalla, E. (1993). Integrating Evolutionary and Social Exchange Perspectives on Relationships: Effects of Gender, Self-Appraisal, and Involvement Level on Mate Selection Criteria. Journal of Personality and Social Psychology, 64, 951-969. http://dx.doi.org/10.1037/0022-3514.64.6.951

Klohnen, E. C., \& Luo, S. (2003). Interpersonal Attraction and Personality: What Is Attractive-Self Similarity, Ideal Similarity, Complementarity or Attachment Security? Journal of Personality \& Social Psychology, 85, 709-722. http://dx.doi.org/10.1037/0022-3514.85.4.709

Kurzban, R., \& Weeden, J. (2005). Hurrydate: Mate Preferences in Action. Evolution and Human Behavior, 26, $227-244$. http://dx.doi.org/10.1016/j.evolhumbehav.2004.08.012

Li, N., \& Kenrick, D. (2006). Sex Similarities and Differences in Preferences for Short-Term Mates: What, Whether, and Why. Journal of Personality and Social Psychology, 90, 468-489. http://dx.doi.org/10.1037/0022-3514.90.3.468

Li, N., Valentine, K., \& Patel, L. (2011). Mate Preferences in the US and Singapore: A Cross-Cultural Test of the Mate Preference Priority Model. Personality and Individual Differences, 50, 291-294. http://dx.doi.org/10.1016/j.paid.2010.10.005

Mays, H., \& Hill, G. (2004). Choosing Mates: Good Genes versus Genes That Are a Good Fit. Trends in Ecology and Evolution, 19, 554-559. http://dx.doi.org/10.1016/j.tree.2004.07.018

Mueller, U., \& Mazur, A. (2001). Evidence of Unconstrained Directional Selection for Male Tallness. Behavioral Ecology and Sociobiology, 50, 302-311. http://dx.doi.org/10.1007/s002650100370

Nettle, D. (2002). Height and Reproductive Success in a Cohort of British Men. Human Nature, 13, 473-491. http://dx.doi.org/10.1007/s12110-002-1004-7

Pawlowski, B. (2003). Variable Preferences for Sexual Dimorphism in Height as a Strategy for Increasing the Pool of Potential Partners in Humans. Proceedings of the Royal Society B: Biological Sciences, 270, 709-712. http://dx.doi.org/10.1098/rspb.2002.2294

Pawlowski, B., Dunbar, R. I. M., \& Lipowicz, A. (2000). Evolutionary Fitness: Tall Men Have More Reproductive Success. Nature, 403, 156. http://dx.doi.org/10.1038/35003107

Place, S., Todd, P., Penke, L., \& Asendorpf, J. (2010). Humans Show Mate Copying after Observing Real Mate Choices. Evolution and Human Behavior, 31, 320-325. http://dx.doi.org/10.1016/j.evolhumbehav.2010.02.001

Prokosch, M., Coss, R., Scheib, J., \& Blozis, S. (2009). Intelligence and Mate Choice: Intelligent Men Are Always Appealing. Evolution and Human Behavior, 30, 11-20. http://dx.doi.org/10.1016/j.evolhumbehav.2008.07.004

Schwarz, S., \& Hassebrauck, M. (2012). Sex and Age Differences in Mate-Selection Preferences. Human Nature, 23, 447466. http://dx.doi.org/10.1007/s12110-012-9152-x

Sear, R. (2006). Height and Reproductive Success. Human Nature, 17, 405-418. http://dx.doi.org/10.1007/s12110-006-1003-1

Shackelford, T., Schmitt, D., \& Buss, D. (2005). Universal Dimensions of Human Mate Preferences. Personality and Individual Differences, 39, 447-458. http://dx.doi.org/10.1016/j.paid.2005.01.023

Stanik, C., Kurzban, R., \& Ellsworth, P. (2010). Rejection Hurts. Evolutionary Psychology, 8, 682-694.

Stulp, G., Buunk, A. P., Pollet, T. V., Nettle, D., \& Verhulst, S. (2013). Are Human Mating Preferences with Respect to Height Reflected in Actual Pairings? PLoS ONE, 8, e54186. http://dx.doi.org/10.1371/journal.pone.0054186

Stulp, G., Pollet, T. V., Verhulst, S., \& Buunk, A. P. (2012). A Curvilinear Effect of Height on Reproductive Success in Human Males. Behavioral Ecology and Sociobiology, 66, 375-384. http://dx.doi.org/10.1007/s00265-011-1283-2

Swami, V., \& Furnham, A. (2008). The Psychology of Physical Attractiveness. Hove: Psychology Press.

Wong, B., \& Candolin, U. (2005). How Is Female Mate Choice Affected by Male Competition. Biological Reviews, 80, 559-571. http://dx.doi.org/10.1017/S1464793105006809

Wood, D., \& Brumbaugh, C. (2009). Using Revealed Mate Preferences to Evaluate Market Force and Differential Preference Explanations for Mate Selection. Journal of Personality and Social Psychology, 96, 1226-1244.

http://dx.doi.org/10.1037/a0015300 
Scientific Research Publishing (SCIRP) is one of the largest Open Access journal publishers. It is currently publishing more than 200 open access, online, peer-reviewed journals covering a wide range of academic disciplines. SCIRP serves the worldwide academic communities and contributes to the progress and application of science with its publication.

Other selected journals from SCIRP are listed as below. Submit your manuscript to us via either submit@scirp.org or Online Submission Portal.

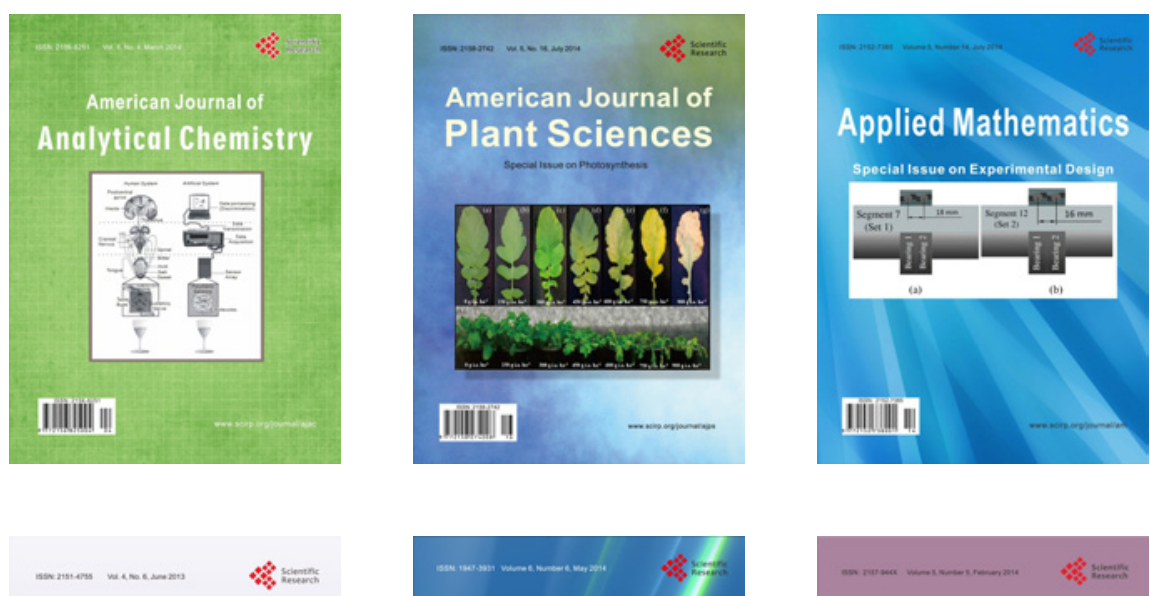

Creative Education
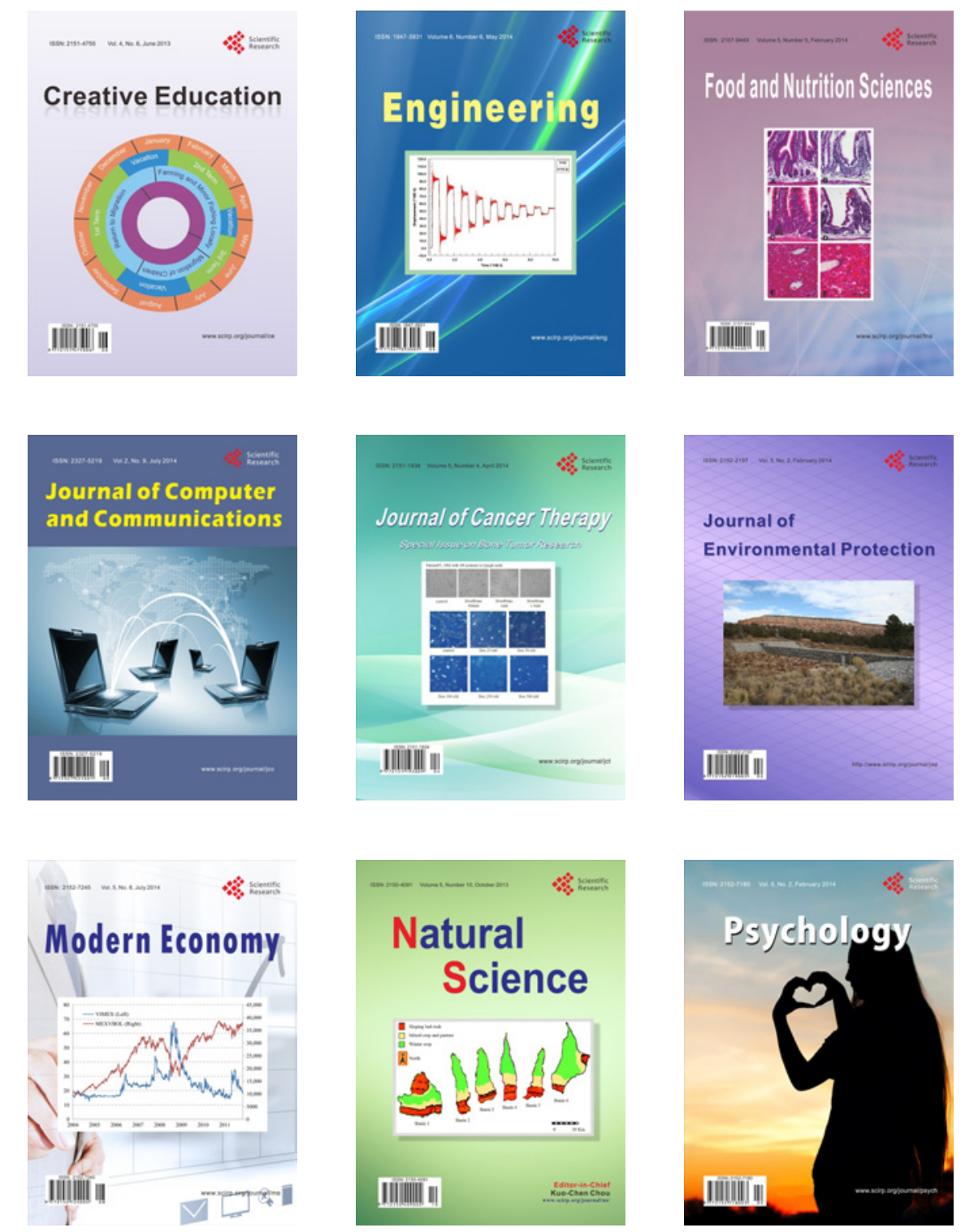